\title{
Vida de jovens: educação não-formal e inserção socioprofissional no subúrbio
}

\author{
Denise Helena P. Laranjeira \\ Universidade Estadual de Feira de Santana, Departamento de Educação \\ Núcleo de Estudos e Pesquisa Trabalho, Tecnologia e Educação
}

\author{
Ana Maria Freitas Teixeira \\ Universidade Federal de Sergipe, Departamento de Educação \\ Grupo de Pesquisa Educação e Contemporaneidade
}

\section{Introdução}

A demanda por mão-de-obra mais escolarizada e mais qualificada é uma das exigências da economia mundial que, desde fins da década de 1980, é regida pelo neoliberalismo. Outros fatores considerados pelos estudiosos, como a redução do papel do Estado nas áreas sociais (a educação é um exemplo), a reestruturação do trabalho, o desemprego estrutural e o aumento do emprego informal vieram afetar dramaticamente a juventude dos setores mais empobrecidos da sociedade. Certamente, os reflexos produzidos a partir da articulação desses fatores mostram-se mais perversos nos países de economia periférica, tal como é o caso do Brasil.

No país, os jovens representam um contingente significativo, aproximadamente 34.081 .330 de pessoas na faixa etária de 15 a 24 anos (IBGE, 2000). No entanto, mais de três décadas distanciam o Brasil dos países ricos no que tange a políticas públicas destinadas a esse segmento.

À luz dessas considerações, a educação é fator estratégico na inserção socioprofissional do jovem, tanto nos países ricos quanto nos pobres (Delors, 1996;
Escot, 1999). No caso brasileiro, o aprofundamento do caráter dual do financiamento do sistema de ensino (público e privado) evidencia o fortalecimento do binômio educação pública/baixos padrões de qualidade. Tal fato acentua as desigualdades na formação dos jovens das camadas mais pobres da população (Charlot, 2000; Freire, 2002; Kuenzer, 2000).

O problema é complexo e suscita diferentes possibilidades de análise, em que se entrecruzam desigualdade social, origem de classe e discriminação étnica. Nessa perspectiva procura-se nortear a presente reflexão, sobretudo quando se percebe que, na cidade de Salvador (BA), a população negra e mestiça é predominante. Some-se a isso o fato de que são nas áreas destituídas ou mal servidas de equipamentos urbanos que crianças e jovens vivem em estado de maior pobreza. Verifica-se que, no campo da educação, o abandono e a repetência escolar reforçam a distorção idade-série, tão comum entre os jovens pobres e negros, colocando em xeque o ensino público do país. Esse quadro expõe os elementos de "tensão e descontinuidade" que caracterizam o percurso escolar da maioria dos jovens das classes desfavorecidas, continuadamente submetidos à experiência do "eterno retorno" 
à escola, ou simplesmente à exclusão do sistema público de educação (Sposito, 1994, p. 166).

$\mathrm{O}$ ingresso precoce no trabalho, o mercado informal, a baixa remuneração e a discriminação étnica participam do conjunto de obstáculos para a inserção socioprofissional dos jovens. De acordo com Pochmann (s.d.), aproximadamente $49 \%$ do desemprego nacional correspondem à faixa etária de 15 a 24 anos, totalizando 3,3 milhões de jovens desempregados no país.

Dados relativos ao desemprego juvenil na Região Metropolitana de Salvador (RMS) expressam a gravidade do problema. Segundo a pesquisa Emprego e Desemprego, no mês de maio de 2005, na RMS, na faixa etária entre 18 e 24 anos, a população desempregada correspondia a $38,9 \%$. No mesmo período, $89,9 \%$ dos desempregados eram constituídos de negros e 10,1\% de brancos (SEI, 2005).

As lacunas do ensino regular e profissional, associadas a tantas outras no plano dos direitos sociais e políticos, no âmbito nacional e local (Salvador), impulsionaram intervenções educativas não-formais em diferentes espaços paralelos à escola (Castro \& Abramovay, 1998; Gohn, 1999). Ao considerar esse panorama em que o Estado brasileiro se exime de seu papel no campo social, trata-se de discutir os limites e as possibilidades da educação não-formal (ENF) no processo de inserção socioprofissional de jovens, como os de Plataforma, bairro do subúrbio ferroviário de Salvador.

Contudo, é imperativo destacar que a multiplicação dessas intervenções, aqui identificadas como não-formais, expressa um amplo espectro de ações que variam desde dispositivos que resultam da iniciativa de organizações locais, tal como associações de moradores, a exemplo do que ocorre em Plataforma, indo até um vasto leque de programas/projetos governamentais em que se observa o frágil equilíbrio entre aspectos inovadores e práticas tutelares em relação aos jovens que compõem o público-alvo: jovens oriundos dos setores populares, entre 14 e 24 anos, predominantemente egressos e/ou evadidos do sistema público de educação, e que, portanto, enfren- tam fortes obstáculos à inserção social no sentido mais abrangente do termo.

Dito de outro modo, a base privilegiada desse conjunto de dispositivos díspares refere-se, de maneira geral, às idéias de vulnerabilidade social, risco e violência, associadas aos jovens pobres. Além disso, um acentuado componente de assistência social está presente nesses programas, tal como nos assinalam Sposito, Carvalho e Souza (2006). Ainda pela perspectiva apontada por esses autores, as múltiplas ações educacionais que transcorrem em paralelo às práticas escolares se difundem amplamente desde a década de 1980, tendo intensa repercussão em meados dos anos de 1990, no segundo mandato do Governo Fernando Henrique Cardoso. Aqui, vale ressaltar que esse conjunto de iniciativas, presumidamente com estatuto de políticas de juventude, traz marcas de descontinuidade, de superposição e de fragmentação. Simultaneamente, a dita "questão social" exige controle e disciplinamento desse público-alvo dos programas, num contexto desfavorável à concepção de políticas de juventude enquanto direito social universal (Camacho, 2004; Sposito \& Corrochano, 2005).

Em contrapartida, todo esse leque de "opções" de programas/projetos, cursos, palestras oferecidos a esses jovens parece constituir mais uma preocupação com o tempo livre dos jovens: é preciso mantê-los sob vigilância, sempre "inseridos" em algum tipo de atividade de "inclusão social", independentemente do seu sentido. Enquanto o estado de moratória social é vivenciado pelos jovens de maior poder aquisitivo, vez que livres para usufruírem do "tempo livre" destinado aos estudos e qualificação, o "tempo livre" não legitimado socialmente é vivido pelos jovens pobres como culpa, sofrimento, convite à criminalidade (Margulis apud Camacho, 2004, p. 5-6).

É nesse cenário que um olhar mais apurado sobre a experiência dos jovens de Plataforma nos permite observar tanto a participação num programa mantido pelo governo federal, ao qual se vincula uma contrapartida financeira, como é o caso do Programa Agente Jovem, como numa ação local encampada pela Associação de Moradores, tal como a Oficina de Teatro. 
Dois objetivos orientaram este trabalho: mostrar o significado do "ser jovem" para esses sujeitos, no bairro de Plataforma, e analisar suas representações sobre a ENF como meio de inserção socioprofissional.

\section{A pesquisa em educação não-formal, inserção socioprofissional e juventude: o desafio da inclusão social}

Em que pesem a extensão e a profundidade dos problemas envolvendo a população jovem da sociedade brasileira, a revisão de literatura indicou a escassez de estudos centrados nas experiências de ENF a partir da representação formulada pelos atores diretamente envolvidos. Como campo de estudo e pesquisa, a interface dos temas juventude, etnia e experiências nãoescolares ainda merece ser explorada (Sposito, 2000). É nessa perspectiva que, no campo conceitual, as categorias ENF e inserção socioprofissional dos jovens ocupam espaço central neste trabalho. No campo metodológico, o aspecto qualitativo norteou a realização de um conjunto de entrevistas.

As diferenças conceituais entre educação formal, não-formal e informal, segundo Delors (1996), inscrevem-se nos princípios da educação ao longo da vida, como entende a Organização das Nações Unidas para a Educação, a Ciência e a Cultura (UNESCO). A educação formal está comumente associada ao poder público e implica freqüência obrigatória, expedição de diploma, entre outros regulamentos. A ENF refere-se às atividades pedagógicas estruturadas e desenvolvidas nos meios não-escolares, de maneira que favoreça a participação na coletividade, a formação dá-se na ação e na perspectiva comunitária. Já a educação informal designa as atividades realizadas sob diferentes contextos (trabalho, casa, rua etc.), sem que a primeira finalidade seja a aprendizagem (Escot, 1999).

O debate sobre a $\mathrm{ENF}^{1}$ está permeado de nuanças (Gohn, 1999; Torres, 1990), tendo em vista a diversi-

${ }^{1}$ Notamos em outros estudos a denominação "educação formal não-convencional" tendo em vista a instituição de práticas pedagógicas do sistema de ensino nessas experiências paralelas à escola (Camacho, 2004; Sposito \& Corrochano, 2005). dade de seu agenciamento e objetivos. Na perspectiva dos autores consultados, os contextos político e socioeconômico têm centralidade, bem como os códigos culturais que participam do processo de construção do saber, cuja finalidade principal é a transformação da sociedade para torná-la mais justa e igualitária (Freire, 2002; Narang, 1992).

As experiências pedagógicas fora do contexto institucional fazem parte das soluções alternativas que têm por objetivo a integração dos jovens "vulnerabilizados", leia-se pobres. A ENF tenta responder às necessidades educativas, sociais e econômicas de uma população pobre e constituída, sobretudo, de jovens e adultos dos países pobres e ricos, segundo a literatura pesquisada (Bélisle, 2001; Delors, 1996; Escot, 1999; Gohn, 1999; Narang, 1992; Sposito \& Corrochano, 2005; Torres, 1990). É importante, pois, ressaltar a dimensão comunitária e emancipatória da ENF como defendida por Narang (1992) e Freire (2002). Nessa perspectiva, valoriza-se a conquista da confiança em si mesmo, a autonomia pessoal, a solidariedade, enfim, a cidadania ativa. O papel do Estado e da sociedade civil é fundamental para dar maior significado a tais práticas. Dessa forma, a adoção de políticas públicas, a exemplo da distribuição de renda e da geração de empregos, são cruciais e não se descolam desses projetos (Camacho, 2004; Castel, 1999; Deniger, 1996).

Num quadro de fluidez e intermitência presentes nas formas institucionalizadas de inserção a que são submetidas essas populações, as intervenções socioeducativas apresentam-se no âmbito cultural, artístico, associativo e/ou voluntário (Roulleau-Berger, 1993; Sposito, 1994, 2000). A formação para além do espaço escolar, por ser propiciadora do engajamento juvenil, necessita ser mais bem conhecida pela óptica dos próprios jovens que participam dessas experiências.

Quanto à discussão sobre a inserção socioprofissional, é necessário, primeiro, observar que a noção de inserção tem caráter multirreferencial. Portanto, pode estar associada ao campo profissional, aos processos de reinserção, às dinâmicas pessoais e psicológicas, às trajetórias de vida e, por fim, à dimensão mais global da inserção (Jellab, 1997). 
Além disso, o declínio e a precarização do trabalho nas últimas décadas, e seus impactos sobre a inserção dos jovens, especialmente dos setores mais pobres e menos escolarizados, são analisados por diferentes estudiosos, alguns dos quais destacaram o componente étnico como um dos fatores mais restritivos à integração desses indivíduos na sociedade (Almeida, 2001; Castel, 1999).

Para esses autores, a ineficácia do Estado, no que diz respeito ao combate às crescentes desigualdades, fragiliza mais ainda essas populações (Castel, 1999) e amplia as situações de risco social. Aliás, vale dizer que tal risco é cada vez menos assumido pelo Estado e cada vez mais pelos próprios indivíduos (Beck, 1996).

Em um cenário com tais singularidades, as alternativas tendem a tornarem-se cada vez mais individualizadas, o que propicia a difusão de uma "cultura da violência", fomentada por uma ordem social excludente, como assinala Espinheira (2003). Não por acaso, expressivamente são os jovens os mais vitimizados nos bairros periféricos dos grandes centros urbanos, como ocorre na cidade de Salvador.

Diante dessa acentuada omissão do Estado, Roulleau-Berger (1993) e Sposito (2000) demonstraram em seus estudos que outras instâncias fora do circuito institucionalizado, a exemplo da escola e do trabalho, passaram a concorrer para a socialização e processos de inserção dos jovens no espaço urbano, inclusive em bairros periféricos. Para essas autoras, as redes de solidariedade e de sociabilidade são tecidas pelos atores individuais e coletivos no contexto urbano.

Apesar de seus limites (descontinuidades dos programas, problemas de ordem financeira, entre outros), essas formas alternativas de inserção, associadas ao campo artístico, cultural, além do trabalho voluntário, sensibilizam a juventude e favorecem a construção de elos identitários e as (re)definições das identidades juvenis (Roulleau-Berger, 1993; Sposito, 1994, 2000).

Dessa forma, importam as expectativas dos jovens em relação ao mundo do trabalho e suas representações sobre esse campo, a partir das experiências vividas na escola e na ENF.
Quanto à definição de juventude, a literatura internacional (Bourdieu, 1980; Bourdon, 2001; Galland, 1991; Pais, 2003) e nacional (Abramo, 2005; Almeida, 2001; Sposito, 1994, 2000) esclarece o sentido de "indeterminação" nessa fase de transição. Tal passagem, não "automática", para a "vida adulta", está relacionada à precariedade das relações de trabalho e à instabilidade do emprego, sobretudo a partir dos anos de 1980 .

A imprecisão do conceito de juventude na realidade brasileira pode ser ilustrada pelo paradoxo apontado por Sposito (2000). De um lado, o prolongamento da faixa etária para 29 anos, ante o adiamento da inserção no mundo do trabalho, e de outro, a inserção precoce (sobretudo na América Latina) no mercado de trabalho em busca do acesso aos bens de consumo, fator decisivo na integração do jovem em seu grupo social, e/ou, ainda de maneira significativa, nos setores mais empobrecidos da sociedade, ante a necessidade de contribuir no orçamento familiar.

Em virtude dessa imprecisão e, conseqüentemente, das ambigüidades que o termo "juventude" comporta, optou-se aqui por denominar os participantes da pesquisa como jovens adultos. Isso porque os princípios de autonomia e responsabilidade são inerentes à inserção do jovem no mundo adulto, ou condição para a ultrapassagem da menoridade (Bourdon, 2001). Ele constitui-se como sujeito de direitos de pertencimento à cidade, portador de subjetividade, necessidades e desejos que lhe são próprios. O ser jovem, de fato, é uma construção social, como reconheceu Bourdieu (1980). Sob circunstâncias psicossociais, culturais e econômicas, materializa-se então o estado adulto ou a maioridade.

\section{O recorte metodológico}

Com base nas contribuições teóricas adotadas e sem perder de vista o foco central da investigação, a abordagem metodológica correspondeu a uma pesquisa de natureza qualitativa descritiva e exploratória, na qual foram utilizadas a entrevista semidirigida e o diário de campo. 
Os estudos de Becker (2000) e Roulleau-Berger (1993) apresentaram-se como perspectivas apropriadas para esta investigação de inspiração etnográfica, realizada no meio natural, em que os processos interativos cotidianos são valorizados pelo pesquisador. As experiências e os sentimentos (inter)pessoais são elementos subjetivos essenciais (Bogdan \& Biklen, 1994) que influenciam as representações que fazem os jovens de suas trajetórias no contexto onde vivem (o bairro de Plataforma, no subúrbio ferroviário da cidade de Salvador). Tratou-se por fim de descobrir como eles se vêem a si próprios (Roulleau-Berger, 1993) e o mundo ao seu redor.

Foram entrevistados dez jovens, em sua maioria negros, entre 17 e 26 anos de idade (quatro homens e seis mulheres). Um membro da diretoria, uma professora de teatro e um padre da paróquia local também participaram da pesquisa.

Todos esses jovens, sujeitos da pesquisa, freqüentavam as oficinas de teatro, de eletricidade, e o Programa Agente Jovem, na Associação de Moradores Chico Mendes (nome fictício). Os temas abordados nas entrevistas versaram sobre a motivação, a aprendizagem, a experiência escolar, os impactos pessoais e sociais das experiências na ENF e os projetos futuros. A inclusão de outros participantes - lideranças comunitárias e educadores - acrescentou informações sobre a realidade cotidiana dos jovens do ponto de vista da família, da escola e do trabalho. Por motivos éticos, os participantes são designados por nomes fictícios.

As três oficinas mencionadas possuem características particulares a serem explicitadas. A de teatro nasce de um programa de extensão da Universidade Federal da Bahia (UFBA). Inexistem certificação e procedimento seletivo. Essa oficina tem por objetivo formar jovens no domínio das artes cênicas; formar multiplicadores nos projetos de arte e educação nos bairros populares. Os jovens desenvolvem atividades três vezes por semana, acompanhados por uma profissional graduada pela UFBA. Eventualmente, "animadores" levam suas contribuições ao grupo, a exemplo da biodança, da oficina de história etc. A oficina de eletricidade é ofertada pela paróquia local em convênio com o Serviço Nacional de Aprendizagem Industrial (SENAI). Existem certificação e processo seletivo, e o objetivo é oferecer uma formação profissional e transmitir princípios de cidadania. ${ }^{2} \mathrm{E}$, por fim, o programa federal Agente Jovem de Desenvolvimento Social e Humano, criado em 2000, vinculado inicialmente ao Plano Nacional de Segurança Pública e ao Programa Nacional de Direitos Humanos, com o objetivo de fortalecer ações direcionadas a prevenir a violência. ${ }^{3}$ Atualmente, é gerido pelo Ministério do Desenvolvimento Social e de Combate à Fome (MDS) (Brasil, 2004). O público-alvo é composto por jovens entre 15 e 17 anos "em situação de risco social", cujas famílias devem comprovar estado de pobreza (renda per capita de até meio salário mínimo). Os jovens recebem uma bolsa mensal no valor de $\mathrm{R} \$ 65,00$, e durante 12 meses devem permanecer na escola e freqüentar cursos de capacitação, sendo acompanhados por "facilitadores" $\mathrm{e}$ "orientadores sociais". ${ }^{5}$ No caso de nossa pesquisa, as responsáveis estudavam em faculdades particulares. Uma cursava Direito, e a outra, a Escola Normal Superior. Outra particularidade observada refere-se à frágil sistematização das atividades: não raro alguns dos jovens se encontravam dispersos, enquanto outros, principalmente as mulheres, se agregavam à oficina de teatro como aprendizes dos mais experientes. Entre os objetivos do projeto estão a preparação dos jovens para

\footnotetext{
${ }^{2} \mathrm{O}$ curso exige freqüência de segunda a sexta-feira. As au-
} las teóricas acontecem nas dependências da Associação de Moradores, e as aulas práticas, nas oficinas do SENAI.

${ }^{3} \mathrm{O}$ programa foi mantido pelo governo do presidente Lula e, segundo dados do Ministério da Previdência e Assistência Social, atinge cerca de 50.000 jovens brasileiros (apud Sposito, Carvalho e Souza, 2006).

${ }^{4}$ Profissionais que se responsabilizariam por oferecer aulas (apud Sposito, Carvalho e Souza, 2006).

${ }^{5}$ Estudantes universitários com experiência em atividades com jovens, preferencialmente ( apud Sposito, Carvalho e Souza, 2006). 
o mercado de trabalho e a inserção nas atividades sociais de sua comunidade, sobretudo na área de saúde, cidadania, meio ambiente etc. (Camacho, 2004). ${ }^{6}$

Para a análise dos dados, mais uma vez os objetivos da pesquisa e a natureza dos instrumentos empregados nortearam a adoção da análise de conteúdo temático (Bardin, 1977). Os dados oriundos do diário de campo e das entrevistas foram ordenados, categorizados e tematizados, permitindo o cruzamento das fontes.

\section{O campo de pesquisa: educação não-formal no subúrbio}

O subúrbio ferroviário de Salvador, particularmente o bairro de Plataforma, marcado pelos contrastes entre a beleza geográfica e a típica pobreza estigmatizante dos bairros "periféricos", bem como por uma rede de organismos de cunho associativo e/ ou comunitário que emergiram, em alguns casos, no período de ascensão dos movimentos sociais, foi o locus escolhido.

Em Plataforma focalizou-se o trabalho desenvolvido pela Associação de Moradores Chico Mendes, fundada em 1977, pioneira na oferta de cursos de iniciação profissional no bairro e referência entre os moradores como rede de apoio para a população trabalhadora.

Esse bairro, um dos mais antigos de Salvador, situa-se à beira do Oceano Atlântico. Constituiu-se como Vila Operária na segunda metade do século XIX, a partir da inauguração da via férrea e instalação de uma fábrica de produtos têxteis, hoje desativada e em ruínas.

Os anos de 1980, conforme Espinheira (2004), marcam mais fortemente a concentração de uma população pobre, que se vai estabelecendo por meio de ocupações ou pelos programas habitacionais governa-

${ }^{6}$ Nas entrelinhas dessa breve descrição do Programa emerge a tensão entre duas visões sobre o jovem: de um lado, vítima e fonte das "questões sociais"; de outro, agente de desenvolvimento em sua comunidade (Pais, 2003). mentais. A precariedade das condições de moradia, de saúde, de educação, de lazer, de cultura e de trabalho acentuou tanto o empobrecimento quanto o agravamento da violência, sobretudo entre os jovens. No bairro de Plataforma, as ocupações predominantes espelham a precariedade do emprego tanto pela sua ausência quanto pelo seu caráter informal. A pesca artesanal, o trabalho doméstico, o pequeno comércio de rua, entre outras ocupações, apresentam-se como alternativas de sobrevivência para homens e mulheres.

\section{Ser jovem em Plataforma e as restrições ao universo sociocultural}

Os principais resultados revelam que, ao abordar a condição de ser jovem, os participantes acusam uma ordem econômica calcada em profundas desigualdades, percebida na imagem de abandono do lugar em que moram.

Os obstáculos para sua inserção socioprofissional são ampliados pela precariedade dos equipamentos urbanos. Enfim, uma estrutura física que os aliena da sociedade urbana contemporânea, o que vem reforçar os déficits de integração (Castel, 1999, p. 538). Para o autor, a discriminação decorrente da origem étnica dificulta a concepção de projetos futuros.

Essa interpretação da realidade fica ilustrada na fala de Soraia (17 anos): "Ser jovem é não ter acesso a uma série de coisas. [...] É você estar consciente que pode ser vítima de violência, você não tem proteção [...]". ${ }^{7}$

As opções de lazer e de práticas esportivas são reduzidas e expressem a ineficácia do poder público. Os jovens demonstraram insatisfação com a falta de quadras de esporte, praças, praias não poluídas. Eles também desejam a reabertura do Cine-Teatro ${ }^{8}$. Estas

${ }^{7}$ Observe-se: a pesquisa "Perfil da Juventude Brasileira" (Abramo \& Branco, 2005, p. 384) assinala que a questão do desemprego e da segurança/violência estão entre os "principais problemas do Brasil hoje" na opinião dos jovens.

${ }^{8}$ Criado pelo Círculo Operário nos anos de 1950, é um dos símbolos do passado industrial de Plataforma. Depois das reivin- 
falas são ilustrativas: "Não tem um cinema no bairro. O Multiplex custa $\mathrm{R} \$ 15,00$; para quem vive no subúrbio os pais não podem pagar [...]" (Yara, 26 anos). Já para Narciso (26 anos), ser jovem "É chato. É cair no pagode aos domingos. [...] É ser um jovem alienado [...]". Ele (único entrevistado que mora só) ainda explica a sua situação de penúria e seus desejos:

Eu pago minhas contas de eletricidade e todas as despesas de casa e digo pra mim: se não compro meu pão eu não como. Sou eu comigo mesmo. Deus, eu e minhas necessidades. Elas vão além de existir e comer. Eu também tenho minhas fantasias: gastar com cosméticos [...], ir a uma festa, ir ao cinema, ir à praia [...], ao porto da Barra [...].

Além disso, na representação desses jovens ficou evidente o problema da disseminação da violência e das drogas. Um dos entrevistados, que teve colegas de infância mortos pela polícia, sublinha:

Para todos aqueles que entram no mundo do crime, a vida é mais curta. [...] As pessoas idosas dizem: "vocês estão na flor da idade!", mas elas não sabem que tem adolescentes que gostariam de saber como é ter a idade delas. Eu gostaria de ter o prazer de aproveitar da terceira idade, se isto for possível, não? (Pedro, 17 anos)

Além disso, segundo Ribeiro (2000), os jovens pobres e negros, não inseridos no mundo do trabalho e da escola, moradores do subúrbio de Salvador, são as principais vítimas da violência. $\mathrm{O}$ contraste dos índices de violência entre os bairros "nobres" e os bairros "periféricos" de Salvador pode ser ilustrado tomando como referência a Barra, ${ }^{9}$ um dos bairros mais citados pelos entrevistados, em oposição à Plataforma.

dicações insistentes do movimento social do bairro, esse espaço foi reformado e inaugurado em dezembro de 2006, agora como Centro Cultural de Plataforma.

${ }^{9}$ Este bairro, situado na Cidade Alta, representa um dos marcos históricos e turísticos de Salvador. Museus, praias apropriadas para banho, bares, hotéis, hospitais, ruas pavimentadas e ilu-
As evocações dos jovens e animadores expõem os contrastes do lugar. Assim, Plataforma também é portadora de uma beleza natural, e alguns dos jovens se orgulham de seu passado. Para a maioria dos jovens, uma barreira socioeconômica e cultural os separa dos jovens da "Cidade Alta", o que simbolizaria a sociedade "integrada" (Becker, 2000; Elias \& Scotson, 2001). Ser morador da "Cidade Baixa" significa não ser reconhecido, isto é, não ser cidadão - em outras palavras, viver a marca da segregação urbana. Como nota Rolnik (2001), as cidades latino-americanas expandiram-se sob a lógica da exclusão e com o aval do poder público. Assim, a configuração da cidade de Salvador seguiu essa mesma lógica, favorecendo a estigmatização dos moradores pobres, e seu enquadramento nas classes perigosas (Espinheira, 2003, p. 75).

\section{A convivência com o (não)trabalho}

Quanto ao trabalho, os jovens revelam suas dificuldades em atender às exigências em relação à escolaridade, à qualificação e à experiência. Um outro elemento que contribui para aprofundar essas dificuldades são os estigmas, que vão além do preconceito de cor e aparência e se estendem ao local de moradia, às drogas, à violência e à pobreza. A intensidade dessa experiência emerge claramente no depoimento de um dos entrevistados:

Eles querem gente bonita para expor na vitrine, os modelos estipulados pela TV. O modelo delicado, branco [...] conforme certas empresas [lojas do shopping] [...]. (Narciso, 26 anos)

Um outro aspecto recorrente no discurso dos jovens são as restrições relativas à escola, e especialmente sua relação com a inserção profissional:

minadas, transporte coletivo etc. configuram o lugar privilegiado do ponto de vista das políticas públicas, se comparado com outros bairros populares. 
A escola pública é difícil de contribuir para o mercado de trabalho porque tem cursos sem professor, não tem livros [...]. O professor, ele mesmo pensa que como é escola pública, ele pode ensinar de qualquer jeito. Como pode nos preparar para o trabalho? [...]. (Pagu, 18 anos)

A confirmação dos estigmas citados está registrada na fala do único jovem que se diferencia pela cor branca de sua pele e pelo nível de escolaridade da mãe (ensino médio completo). Para ele, as dificuldades de emprego não estavam relacionadas a seus atributos pessoais e lugar de moradia, mas à ausência de ofertas de emprego no subúrbio, distintamente de outros bairros mais centrais de Salvador.

A polaridade "Cidade Alta" e subúrbio ferroviário, tão presente no imaginário dos jovens, exprime a segmentação socioprofissional e cultural (Kuenzer, 2000; Sposito, 2000). Nesse sentido, as políticas públicas não reconhecem os jovens como sujeitos de direito ao trabalho, ao lazer, à educação etc. É a partir dessa ausência de reconhecimento que os jovens vão construir a representação de si mesmos no espaço urbano.

Todos os jovens entrevistados desejariam obter uma inserção profisssional, seja por meio de um estágio, seja no trabalho formal e/ou associativo. Ao fim do trabalho de campo, apesar das dificuldades expressas pelos jovens, pôde-se constatar um movimento diferenciado nas suas trajetórias, a exemplo da inserção no trabalho associativo; nas atividades de estágio remunerado; no mercado formal, no campo da saúde. A inserção provisória e de baixa remuneração, tal como se evidencia, ainda resta como alternativa mais comum entre os jovens, o que é confirmado pelos entrevistados.

A desilusão perante o destino socioprofissional (Bourdieu, 2001; Galland, 1991) foi registrada com freqüência. Pedro (17 anos) constata sua desilusão com as profissões de advogado e de médico. Ele atribui para si o destino de padeiro ou de vendedor ambulante. Os efeitos desse "desencantamento" podem também provocar o sentimento de impotência e conformismo ante uma situação que lhe parece intrans- ponível. Tanto para certos jovens contatados como para outros entrevistados, o conformismo, a acomodação e o sentimento de impotência seriam característicos na juventude do bairro.

\section{A escola e seus limites para a inserção social e profissional}

Cumpre observar que os/as jovens sujeitos da pesquisa são oriundos ou ainda freqüentam a escola pública, razão pela qual há em suas falas referências sobre o modelo formal/oficial de escola e seus limites. Esse aspecto possibilitou comparar as experiências escolares e não-escolares vivenciadas por eles. As atividades e relações pedagógicas inovadoras presentes no espaço "não-convencional" resultam numa postura crítica em relação à escola, fato assinalado por Sposito e Corrochano (2005, p. 164).

Segundo os jovens pesquisados, a escola pública e sua prática pedagógica estão distantes de seus interesses e de seu cotidiano. Por isso não os mobiliza, não escuta suas demandas, nem os habilita profissionalmente. Entre as representações dos jovens foi possível notar a incomunicabilidade entre professores e estudantes, como relata Moema (20 anos), concluinte do ensino médio:

A professora está lá para passar conhecimento aos alunos que ficam lá sentados [...] eu mesmo não tenho paciência de ficar assim sentada lendo [...] Eu vou me formar em quê? Formação geral de quê? O governo pensa que o jovem é besta, idiota em relação à escola? Não interessa que o jovem saiba e aprenda alguma coisa, mas que passe rápido de ano [...] eu saio do colégio sem saber nada.

O conjunto dos depoimentos também revela a constatação de que o acesso à educação formal não traduz por si só a inserção social e profissional dos jovens (Pochmann \& Amorim, 2003). Ao contrário, acaba por reafirmar a segmentação sociocultural e profissional (Kuenzer, 2000). Ademais, concordamos com Sposito e Corrochano (2005) quanto à ausência de articulação entre as práticas pedagógicas inovado- 
ras nos espaços "não-convencionais" e formais, e destas com as políticas públicas.

Como notam Abramo (2005), Almeida (2001) e Deniger (1996), Estado e sociedade responsabilizam o indivíduo pelo fracasso, dissimulando a natureza política dos problemas nessa esfera. Com efeito, o jovem sente-se responsável por seu fracasso, da mesma maneira que o êxito socioprofissional é atribuído ao próprio indivíduo.

\section{Educação não-formal como proposta de inclusão social}

É importante salientar que a representação dos jovens sobre a escola pública foi fundamental para, no presente estudo, compreender suas representações sobre a ENF. Quando se trata de estabelecer as relações entre ENF e inserção socioprofissional, os entrevistados exprimiram os aspectos positivos de suas experiências nas oficinas e mostraram que a ENF ocupa um lugar preponderante em suas trajetórias de vida.

As mudanças no seio das relações sociais e nas atitudes em relação a si mesmos pareceram ter constituído um repertório importante nesse percurso de vida, traduzido pela busca de autonomia e responsabilidade. Acrescente-se que, na representação de diversos jovens, a ENF contrasta com a experiência escolar e também os reconcilia com a aprendizagem. Assim, para os jovens, as experiências nas oficinas, além de um espaço de aprendizagem, configuram um espaço de pertencimento, isto é, um fator "de proteção e proximidade" (Castel, 1999, p. 535), num contexto adverso de pobreza e risco social.

\section{As aprendizagens: o "saber ser", o fazer e o engajamento}

Um outro elemento relevante que se destaca em todos os depoimentos desses jovens refere-se ao papel da ENF: apoiar o seu desenvolvimento pessoal, interferindo positivamente em sua sociabilidade. $\mathrm{O}$ "saber ser", expressão empregada por um dos jovens quando da avaliação de sua vivência nas oficinas, contempla um dos principais temas deste estudo. Segundo Moema (20 anos): "Cada vez mais eu compreendo melhor as coisas, o cotidiano. Eu desenvolvi, nesta experiência, o escutar o outro, e agora compreendo melhor o que uma pessoa me diz [...]".

Os jovens percebem-se como atores, ocupam um lugar no grupo. É aí que se encontra a idéia de engajamento, produzido pela aprendizagem dialógica (Freire, 2002) e pela ação.

$\mathrm{O}$ apoio emocional exercido entre eles próprios e com os animadores permitiu-lhes criar uma rede presente nas relações interpessoais e de aprendizagem. O elo integrador com o outro e com o meio significou para eles a possibilidade de sair da invisibilidade, ser reconhecido, enfim, a criação de novas sociabilidades em bases mais solidárias e coesas.

Contrariamente ao que se passa na experiência escolar, a maioria dos jovens mostrou interesse e implicação nas atividades. Conforme certos depoimentos, na escola sentem-se "obrigados a aprender", enquanto a vivência na oficina é associada aos estados de "sedução" e de "prazer". Eles manifestam contentamento e surpresa quando descobrem novas habilidades nessa experiência. A aprendizagem motiva, porque possui uma significação para o jovem, e integra-se à vida cotidiana, favorecendo a confiança em si e a esperança. Não por outro motivo, jovens de Plataforma pareceram em sua maior parte ter certo "poder de implicação" (Jellab, 1997, p. 88), intervindo na experiência vivida na oficina, como também em outros espaços.

É nesse contexto de valorização identitária, aqui compreendido em sua dimensão étnica e social, que os estigmas de inferioridade podem ser reduzidos. Para retomar uma formulação de um deles, é necessário "buscar seu lugar ao sol", o que exige uma ação engajada visando à transformação de si mesmo e de seu espaço.

O fato de não se considerar os jovens como vítimas (Zaluar, 1994), mas, antes de tudo, como sujeitos igualmente responsáveis por seu destino, parece ter contribuído para o engajamento juvenil. A ocupação de outros espaços fora do bairro, como revelaram 
os participantes, parece ter significado uma "ampliação do horizonte social dos jovens que acabam saindo do círculo familiar mais estreito, da rede de vizinhos mais próximos, da sua rua, ou praça, ou bairro, ou seja, de redes de sociabilidade que vão integrá-los à cidade" (idem, p. 65). Essas novas incursões, como revelam os animadores, parecem favorecer o fortalecimento de sua identidade pessoal e social. Eles podem assim conquistar a estima de si mesmos, a autoconfiança, e neutralizar as imagens estigmatizantes com respeito a eles próprios e a seu bairro, a partir das iniciativas culturais (Espinheira, 2003; RoulleauBerger, 1993; Sposito, 2000).

\section{Conclusão}

Ao debruçar-se sobre o conjunto dos temas que emergiram durante as entrevistas com os jovens, analisando a maneira como falam de si mesmos, as recorrentes palavras e expressões usadas para desenhar o retrato do "jovem do subúrbio", o "jovem da Cidade Baixa", observou-se que um conjunto de fatores compromete essa imagem de si mesmos, com a internalização do estigma de inferioridade. É pelo olhar do outro que os jovens adultos de Plataforma se percebem inferiores. Vários dos entrevistados denunciaram os estereótipos negativos, tal como o de "marginais", dirigido aos estudantes da escola pública.

Para Elias e Scotson (2001), os "símbolos de inferioridade" são veiculados pelos grupos sociais reconhecidos como "superiores". Os estigmas de inferioridade traduzem as "imagens coletivas" de caráter "negativo" que, inculcadas com o tempo, afetam a auto-estima, a dignidade e o amor próprio.

Observou-se como diferencial demarcador entre a escola pública e a ENF as práticas e interações estabelecidas nas oficinas. A oficina de teatro manifestou uma força "catalisadora" no espaço comunitário. As múltiplas formas de linguagem no campo artístico e cultural despertam a curiosidade dos jovens. Sua singularidade não se limita à integração dos jovens no mundo sensível e corporal da arte, mas, antes de tudo, nos elos de natureza pedagógica e política que favore- cem o desenvolvimento de uma ação reflexiva sobre si e seu entorno. É por meio das atividades artísticas que se (re)integram consigo próprios e com o outro.

Do ponto de vista da educação profissional, os jovens da oficina de eletricidade têm um tipo de formação diferenciado, vez que, na aprendizagem pelo agir, eles podem ter acesso a um conhecimento técnico e científico compatível com certas exigências do mercado de trabalho. O curso prático de algumas matérias, como informática e eletroeletrônica, ocorre em outro espaço físico, o SENAI, reconhecido como importante formador de mão-de-obra nos níveis básico, médio e superior. Enquanto outros jovens de outras oficinas aspiram ao domínio da informática, mas sem acesso a esse curso, suas famílias e/ou eles próprios, com dificuldades, pagam um curso privado nessa área.

Nesse sentido, os programas ligados ao governo federal, a exemplo do Agente Jovem, mesmo portando ganhos de ordem material, por meio de uma bolsa mensal, e contribuindo para a elevação da autoestima do público-alvo, adotam, entretanto, uma perspectiva mais compensatória que crítica. Conforme nos indicam Sposito e Corrochano (2005), o Programa Agente Jovem insere-se nos princípios que têm norteado as políticas públicas brasileiras direcionadas aos jovens, conjugando de forma criticável os mecanismos de transferência de renda (bolsa mensal) e a exigência de uma contrapartida ${ }^{10}$ obrigatória desses jovens (freqüência/retorno à escola, realização de ati-

${ }^{10} \mathrm{O}$ aspecto da contrapartida, conforme a abordagem das autoras, apresenta-se como falso, porquanto inexiste melhoria efetiva do sistema público de ensino que favoreça a inclusão social. A propósito, o documentário Pro dia nascer feliz (de 2005, dirigido por João Jardim) ilustra com fidelidade o cotidiano escolar dos/das jovens estudantes de escolas públicas em algumas cidades brasileiras, tomando como contraponto o universo do sistema de ensino privado, freqüentado por uma classe social mais abastada. Os diversos destinos socioprofissionais, claramente demarcados nesse contexto de (re)produção e aprofundamento das extremas desigualdades, são anunciados pelos próprios entrevistados. 
vidades comunitárias etc.). Apesar de inegável o beneficio trazido pelo acesso à renda, as autoras assinalam que a difusão dessa lógica nas ações púbicas pode incorrer em "novas formas de dominação". Nessa mesma direção, Camacho (2004) e Sposito, Carvalho e Souza (2006) apontam que as primeiras avaliações sobre esses programas indicam que, em geral, as atividades são realizadas em condições materiais precárias, assim como é precária a formação técnica e escolar de seus responsáveis. A esse arranjo - em que se conjugam palestras, oficinas, formação para o trabalho e prestação de serviços à comunidade - Leão (2004) denomina de "pedagogia da precariedade". Embora esteja presente o discurso da inclusão social entre os promotores oficiais e "comunitários", tais práticas "podem acentuar mecanismos perversos de reprodução de uma base humana e material precária [...] reiterando a idéia de que não é preciso oferecer muito aos pobres" (Sposito \& Corrochano, 2005, p. 161).

Detectou-se também que a ENF reproduz práticas da escola tradicional, muitas vezes em razão das demandas de certos jovens, como, por exemplo, a exigência de maior disciplina. Ressalte-se que a experiência educativa de alguns animadores incorpora traços da referida formação tradicional, mais associada à educação formal. As contradições estão presentes, portanto, na ENF, mesmo que esta proponha a afirmação identitária e a inclusão. No caso da oficina Agente Jovem, ratifica-se, involuntariamente, a etiqueta de excluído e reforça-se a condição de jovem estigmatizado (Goffman, 1988).

Ainda quanto aos programas federais, deve-se destacar a falta de uma formação profissional mais específica e práticas de aprendizagem sistematizadas que permitiriam desenvolver as habilidades de leitura e escrita. Constata-se, todavia, que tais ações não seriam suficientes para preencher as condições de "plena integração" social (Castel, 1999; Jellab, 1997), vez que restam as lacunas das políticas públicas eficazes e capazes de contribuir para a superação do estado de vulnerabilidade do jovem.

Com referência aos programas governamentais mais recentes, que objetivam inserir profissionalmente o jovem oriundo dos setores desfavorecidos, até o momento não é possível registrar impactos qualitativos ante a grave situação de desemprego que afeta a população juvenil, particularmente, quando se trata da Região Nordeste e dos subúrbios das grandes cidades, onde se encontram os mais altos índices de exclusão de pessoas nessa faixa etária.

É nesse contexto de incerteza concernente à inserção pelo trabalho e de fragilidade na formação identitária do jovem por instituições como a família e a escola que as experiências da ENF parecem representar uma alternativa de inclusão social para a maior parte dos jovens.

Por fim, esse "novo" tipo de inclusão, ainda que intermitente e pouco visível, é parte importante dessa realidade, e não poucas vezes se constitui na única opção de pertencimento encontrada pelos jovens. Uma possibilidade, portanto, de projetar "algum" futuro.

A multiplicação de espaços educacionais nãoformais direcionados aos jovens certamente ampliaria seus reflexos positivos, desde que articulada a políticas públicas conseqüentes. Afinal, como indica o conjunto dos estudos, apesar das diferenças existentes em termos econômicos e socioculturais, em países como o Brasil as desigualdades sob o neoliberalismo e o fenômeno do empobrecimento dos jovens são parte de uma realidade sem fronteiras.

\section{Referências bibliográficas}

ABRAMO, Helena Wendel. Condição juvenil no Brasil contemporâneo. In: ABRAMO, Helena Wendel; BRANCO, Pedro Paulo Martoni (Orgs.). Retratos da juventude brasileira: análises de uma pesquisa nacional. São Paulo: Fundação Perseu Abramo/Instituto Cidadania, 2005. p. 37-72.

.; BRANCO, Pedro Paulo Martoni. Perfil da juventude brasileira. In: . (Orgs.). Retratos da juventude brasilei$\mathrm{ra}$ : análises de uma pesquisa nacional. São Paulo: Fundação Perseu Abramo/Instituto Cidadania, 2005.

ALMEIDA, Elmir. Política pública para a juventude: proposta para uma "moderna condição juvenil". 2001, 325f. Tese (Doutorado em Educação) - Faculdade de Educação, Universidade de São Paulo, São Paulo, 2001. 
BARDIN, Laurence. L'analyse de contenu. Paris: Presses Universitaires de France, 1977.

BECK, Ulrich. Risk society. Towards a new modernity. Berkeley: Sage Publication, 1996.

BECKER, Howard S. Outsiders: études de sociologie de la deviance. Paris: A. M. Métaille, 2000.

BÉLISLE, Rachel. Des rapports pluriels à l'écrit. Rapport de recherche aux partenaires sur la culture de l'écrit d'organismes communautaires d'insertion et professionnelle qui proposent des projets de formation à des jeunes adultes non diplômés. Québec: Université de Sherbrooke, 2001.

BOGDAN, Robert C.; BIKLEN, Sari Knopp. Investigação qualitativa em educação: uma introdução à teoria e aos métodos. Porto: Porto Editora, 1994. (Coleção Ciências da Educação).

BOURDIEU, Pierre. La jeunesse n'est qu'un mot. In: Question de sociologie. Paris: Minuit, 1980. p. 143-155. Meditações pascalianas. Trad. Sérgio Miceli. Rio de Janeiro: Bertrand Brasil, 2001.

BOURDON, Sylvain. Les jeunes de l'école à l'emploi: l'hiperactivité comme adaptation à la précarité au Québec. In: ROULLEAU-BERGER, Laurence; GAUTHIER, Madeleine (Orgs.). Les jeunes et l'emploi dans les villes d'Europe et d'Amerique du Nord. Paris: Edition de l'Aube, 2001. p. 73-85.

BRASIL. Ministério do Desenvolvimento Social e Combate à Fome (MDS). Projeto Agente Jovem de Desenvolvimento Social e Humano. 2004. Disponível em: <www.mds.gov.br>. Acesso em: 30 jun. 2007.

CAMACHO, Luiza. Projeto Agente Jovem: ação, programa ou política pública de juventude? In: REUNIÃO ANUAL DAANPEd, 27., 2004, Caxambu. Anais... Caxambu: ANPED, 2004. 1 CDROM.

CASTEL, Robert. As metamorfoses da questão social: uma crônica do salário. 2. ed. Petrópolis: Vozes, 1999.

CASTRO, Mary Garcia; ABRAMOVAY, Miriam. Cultura, identidades e cidadania: experiências com adolescentes em situação de risco. In: BRASIL. Ministério do Planejamento e Orçamento. Jovens acontecendo na trilha das políticas públicas. Brasília: CNPD, 1998. p. 571-642.

CHARLOT, Bernard. A relação ao saber e à escola dos alunos dos bairros populares. In: AZEVEDO, José Clóvis de; GENTILI, Pablo; KRUG, Andréa; SIMON, Cátia. (Orgs.). Utopia e democracia na educação cidadã. Porto Alegre: Ed. Universidade/UFRGS/Secretaria Municipal de Educação, 2000. p. 245-257.
DELORS, Jacques (Org.). La educación encierra un tesoro. Informe a la UNESCO de la Comissión Internacional sobre la educación para el siglo XXI. Madri: Santillana/UNESCO, 1996. DENIGER, Marc. André. Crise de la jeunesse et transformations des politiques sociales en contexte de mutation structurale. Sociologie et Sociétés, v. 28, n. 1, p. 73-88, 1996.

ELIAS, Norbert; SCOTSON, John L. Logiques d'exclusion. Trad. Pierre Emmanuel Dauzat. Paris: Fayard, 2001.

ESCOT, Claude. La culture scientifique et technologique dans l'éducation non formelle. Paris: UNESCO, 1999.

ESPINHEIRA, Gey. Conflito e convivência na cultura da violência: periferia e pobreza. In: ESPINHEIRA, Gey; CARVALHO, Antônio Mateus de (Orgs.). Desenvolvimento comunitário bairro de Plataforma. Salvador: Universidade Federal da Bahia, Centro de Recursos Humanos, 2003. p. 67-76.

(Org.). Sociabilidade e violência: criminalidade no cotidiano de vida dos moradores do Subúrbio Ferroviário de Salvador. Salvador: Ministério Público do Estado da Bahia/Universidade Federal da Bahia, 2004.

FREIRE, Paulo. Pedagogia da autonomia: saberes necessários à prática educativa. Rio de Janeiro: Paz e Terra, 2002.

GALLAND, Olivier. Sociologie de la jeunesse: l'entrée dans la vie. Paris: Armand Colin Éditeur, 1991.

GOFFMAN, Erving. Estigmas: notas sobre a manipulação da identidade deteriorada. Rio de Janeiro: LTC, 1988.

GOHN, Maria da Glória. Educação não-formal e cultura política. São Paulo: Cortez, 1999. (Coleção Questões da Nossa Época).

IBGE - Instituto Brasileiro de Geografia e Estatística. Censo demográfico. 2000. Disponível em: $<\mathrm{http}: / / w w w . i b g e . g o v . b r>$. Acesso em: 16 mar. 2006.

JELLAB, Aziz. La mission locale face aux jeunes. Quelle socialisation pour quelle insertion? Cahiers Internationaux de Sociologie, Paris, n. 102, p. 86-106, 1997.

KUENZER, Acacia Zeneida. Educação cidadã, trabalho e desemprego: o possível como caminho para a utopia. In: AZEVEDO, José Clóvis de; GENTILI, Pablo; KRUG, Andréa; SIMON, Cátia (Orgs.). Utopia e democracia na educação cidadã. Porto Alegre: Ed. Universidade UFRGS/Secretaria Municipal de Educação, 2000. p. 353-368.

LEÃO, Geraldo. A gestão da pobreza juvenil: uma análise de um programa federal de inclusão social para jovens pobres. In: REUNIÃO ANUAL DA ANPEd, 27., 2004, Caxambu. Anais... Caxambu: ANPEd, 2004. 1 CD-ROM. 
NARANG, Renuka H. Social justice and political education through non-formal education. International Review of Education, v. 38 . n. 5, p. 542-546, 1992.

PAIS, José Machado. Culturas juvenis. 2. ed. Lisboa: Imprensa Nacional Casa da Moeda, 2003.

POCHMANN, Márcio. Desemprego é a grande ameaça ao jovem entre 15 e 24 anos. s.d. Disponível em: <http://www.educacional. com.br>. Acesso em: 2 ago. 2005.

.; AMORIM, Ricardo (Orgs.). Atlas da exclusão social no Brasil. São Paulo: Cortez, 2003.

RIBEIRO, Lutz Mulert S. Pesquisa sobre crimes de homicídio na Bahia. In: OLIVEIRA, Nelson de; RIBEIRO, Lutz Mulert S.; ZANETTI, José Carlos (Orgs.). A outra face da moeda. Violência na Bahia. Salvador: Comissão de Justiça e Paz da Arquidiocese de Salvador, 2000. p. 70-100.

ROLNIK, Raquel. O que é cidade. 3. ed. São Paulo: Brasiliense, 2001 (Coleção Primeiros Passos).

ROULLEAU-BERGER, Laurence. La ville intervalle. Jeunes entre centre et banlieu. Paris: Meridien Klincksieck, 1993.

SEI - Superintendência de Estudos Econômicos e Sociais da Bahia. Pesquisa emprego e desemprego (PED). 2005. Disponível em: $<$ http://www.sei.ba.gov.br>. Acesso em: 20 dez. 2005.

SPOSITO, Marília Pontes. A sociabilidade juvenil e a rua: novos conflitos e ação coletiva na cidade. Tempo Social - Revista de Sociologia da USP, São Paulo, v. 5, n. 1-2, p. 161-178, 1994.

. Juventude: crise, identidade e escola. In:

Estudos sobre movimentos sociais, juventude e educação. São Paulo: Faculdade de Educação, Universidade de São Paulo, 2000. p. 144-193.

.; CORROCHANO, Maria Carla. A face oculta da transferência de renda para jovens no Brasil. Tempo Social - Revista de Sociologia da USP, São Paulo, v. 17, n. 2, p. 141-172, nov. 2005.

SPOSITO, Marilia Pontes; CARVALHO, Hamilton Harley de; SOUZA, Nilson Alves. Juventude e poder local: um balanço de iniciativas públicas voltadas para jovens em municípios de regiões metropolitanas. Revista Brasileira de Educação, v. 11, n. 32, p. 238-257, maio/ago. 2006.

TORRES, Carlos Alberto. The politics of non-formal education in Latin America. New York: Praeger Publishers, 1990.

ZALUAR, Alba. Cidadãos não vão ao paraíso. São Paulo: Escuta; Campinas: Editora da UNICAMP, 1994.
DENISE HELENA P. LARANJEIRA, socióloga, doutora em educação pela Universidade de Sherbrooke - Québec (Canadá), é professora adjunta do Departamento de Educação da Universidade Estadual de Feira de Santana (UEFS) e coordenadora do curso de especialização em Educação e Pluralidade Sociocultural na mesma universidade. Publicações recentes: em co-autoria com Ceci V. Noronha, Eduardo M. Paes, Gino Taparelli, Tânia R. F. Cordeiro e Carlos A. T. Santos: "Violência, etnia e cor: um estudo dos diferenciais na região metropolitana de Salvador" (Revista Panamericana de Salud Pública, v. 5, p. 268-277, abr./mayo 1999); "O trabalho no mundo contemporâneo: a organização burocrática e seu impacto sobre o corpo do trabalhador" (In: CABEDA, Sonia T. L.; CARNEIRO, Nádia V.; LARANJEIRA, Denise H. P. O corpo ainda é pouco. II Seminário sobre a contemporaneidade. NUC/ UEFS, 2000, p. 253-264); em co-autoria com Ana Maria F. Teixeira e Sylvain Bourdon: "Juventude, trabalho, educação: os jovens são o futuro do Brasil?" (Caderno CRH, Salvador, v. 20, n. 49, p. 95105, jan./abr. 2007). Coordenadora do Núcleo de Estudos e Pesquisa: Trabalho, Tecnologia e Educação (NETTE), desenvolvendo a pesquisa "Velhos e jovens da terra: encontro entre tempos, memórias e saberes".E-mail: denise.laranjeira@gmail.com

ANA MARIA FREITAS TEIXEIRA, socióloga, doutora em ciências da educação pela Universidade Paris VIII, é professora adjunta do departamento de educação da Universidade Federal de Sergipe e orientadora do curso de especialização em Educação e Pluralidade Sociocultural na mesma universidade. Publicações recentes: "A cigarra e a formiga: qualificação e competência - um balanço crítico" (Revista Brasileira de Informação Bibliográfica em Ciências Sociais, n. 61, 1. sem. 2006); em co-autoria com Ana Maria F. Teixeira e Sylvain Bourdon: "Juventude, trabalho, educação: os jovens são o futuro do Brasil?" (Caderno CRH, Salvador, v. 20, n. 49, p. 95-105, jan./abr. 2007.). Pesquisadora do Grupo de Estudos e Pesquisas Educação e Contemporaneidade, vinculado ao Mestrado em Educação (NPGED/UFS). Pesquisa em andamento: "Trajetórias de jovens: educação profissional e mudanças no mundo do trabalho", financiada pelo Conselho Nacional de Desenvolvimento Científico e Tecnológico (CNPq). E-mail: a.f.teixeira@terra.com.br

Recebido em outubro de 2006 Aprovado em junho de 2007 
Denise Helena P. Laranjeira e

Ana Maria Freitas Teixeira

Vida de jovens: educação não-formal e inserção socioprofissional no subúrbio

Analisa as práticas educativas paralelas à escola formal, vivenciada por jovens do subúrbio de Salvador, com foco na inserção socioprofissional. Trata-se de considerar os reflexos das experiências desenvolvidas no espaço da Associação de Moradores, referência no bairro, envolvendo os jovens das Oficinas de Teatro, do Curso de Eletricidade e do Programa Agente Jovem. A opção pelo subúrbio apóia-se nos estudos que indicam a maior ausência do Estado nesses cenários onde se concentra a população jovem desfavorecida social e culturalmente. Nesses espaços "esquecidos", eles enfrentam diferentes estigmas que afetam diretamente seu processo de inserção socioprofissional.

Palavras-chave: juventude; educação não-formal; inserção socioprofissional

\section{Young people's lives: non-formal education and socio-professional insertion in the suburbs}

The article analyses non-formal education practices amongst young people in a suburb of Salvador, focussing on socio-professional insertion. It centres on experiences involving young people in Theatre Workshops, an Electricity Course and the Youth Agent Programme carried out in the space of a local Residents' Association, considered as an important reference in the district. The choice of an urban suburb reflects studies showing that this is where the State is largely absent and where economically and culturally disadvantaged young people are concentrated. In these "forgotten" spaces they confront stigmas which directly affect their socio-professional insertion.

Key words: youth; non-formal education; socio-professional insertion

Vida de jóvenes: educación no

formal e inclusión socio profesional en el suburbio

Analiza las prácticas educativas paralelas a la escuela formal, vivenciadas por jóvenes del suburbio de Salvador, enfocando la inclusión socio-profesional. Se trata de considerar los reflejos de las experiencias desarrolladas en el espacio de la Asociación de Vecinos, referencia en el barrio, envolviendo los jóvenes del Taller de Teatro, del Curso de Electricidad y del Programa Agente Joven. La opción por el suburbio se apoya en los estudios que indican la mayor ausencia del Estado en esos escenarios donde se concentra la población joven desfavorecida social y culturalmente. En esos espacios "olvidados", ellos enfrentan diferentes estigmas que afectan directamente su proceso de inclusión socio profesional. Palabras claves: juventud; educación no formal; inclusión socio-profesional 